\title{
Case Study of Mental Health Education Teacher Preparation from the Perspective of Ideological and Political Theory Education in China
}

\author{
Jilin Zou ${ }^{1}$ Chengyan Yang,** \\ ${ }^{1}$ Department of Psychology, School of Education, Linyi University, Shandong Province, China \\ ${ }^{*}$ Corresponding author. Email: zoujl@lyu.edu.cn
}

\begin{abstract}
Department of Psychology, School of Education at Linyi University trained mental health education teacher of primary and secondary schools whose major is Applied Psychology. After years of practice and exploration, we summed up a new model of mental health education teacher preparation, aiming to strengthen the ideological and political theory education. Firstly, we took "Four Haves" good teachers as the standard. Secondly, we took the cultivation of teachers' ethics as the core. Finally, we divided the cultivation of teachers' ethics into three dimensions (moral cognition, moral emotion and moral willpower) in theory, and in practice, we adopted multiple of strategies simultaneously such as innovating teaching practicum and curriculum design for the three dimensions and encouraging our teacher educators to do social service activities and our student teachers to do service learning.
\end{abstract}

Keywords: Teacher preparation, Mental health education, Ideological and political theory, Teachers' ethics

\section{INTRODUCTION}

In December 2019, seven ministries and commissions including Ministry of Education in China jointly issued "Notice on Strengthening and Improving the Construction of Teachers' Ethics and Virtue in the New Era" (Teacher 〔2019〕 No. 10), which clearly requires: "Teacher's morality education should run through the whole process of teacher preparation and their teaching career. Student teachers must learn the course of teachers' ethics education, and in-service teachers training should include special topic about teachers' ethics education in each year." [1]

Pre-service teacher preparation for mental health education in primary and secondary schools was completed in Department of Psychology, School of Education at Linyi University. Meanwhile, because of its professional nature of helping others and self-help, mental health education is originally a profession with higher requirements about morality and ethics, so the cultivation of ethics of mental health education teachers is more important.
So how to infuse ideological and political theory education into training of the professional ethics of mental health education teachers?

From perspective of ideological and political theory education, after many years of practice and exploration, we have summed up a new model consisting of "one core, three dimensions" in preparing "Four Haves" good teachers in mental health education. That is to say, taking "Four Haves" good teachers who have socialist ideals and beliefs, noble moral sentiments, solid knowledge and kindly benevolence as the standard [2], and taking the cultivation of teachers' ethics as the core. Moreover, we used scientific research advantages of our major, and divided teachers' ethics into three dimensions (moral cognition, moral emotion and moral willpower) in theory according to the psychological principles of moral education. In practice, under the guidance of Communist Party branch of Department of Psychology, we revised the cultivation objectives many times around cognition, emotion and willpower of teacher ethics in order to cultivate "Four Haves" good teachers of mental health education in three dimensions. In a word, we have adopted multiple of strategies simultaneously such as innovating teaching practicum and curriculum system for the three dimensions, and encouraging our teacher 
educators to do some social services and our student teachers to do some public services learning for a long time. This paper used the case study method to discuss the implementation of these strategies in detail below.

\section{METHOD}

Our case study selected Department of Psychology at Linyi University as a typical sample case. We used secondary data analysis method [3] to analyse historic documents, survey, interview data on the development of Department of Psychology for three reasons: (1) Linyi University is located in the revolutionary base area of China and has a fine tradition of ideological and political theory education, (2) Linyi University has a perfect documents and archives management system, whose graduates' interviews, surveys, historic documents and other tracking data are well preserved, (3) One of authors of this paper is the Associate Dean of Department of Psychology, who has witnessed the development of the department and has access to get various tracking data of the graduates.

\section{FINDINGS}

Firstly, through analysing the historic documents, we summed up the achievements of teacher education and advanced a new model consisting of "one core, three dimensions" in mental health education teacher preparation. In this model, we regarded the cultivation of teacher's ethics as the core, which have three dimensions: moral cognition, moral emotion, and moral willpower.

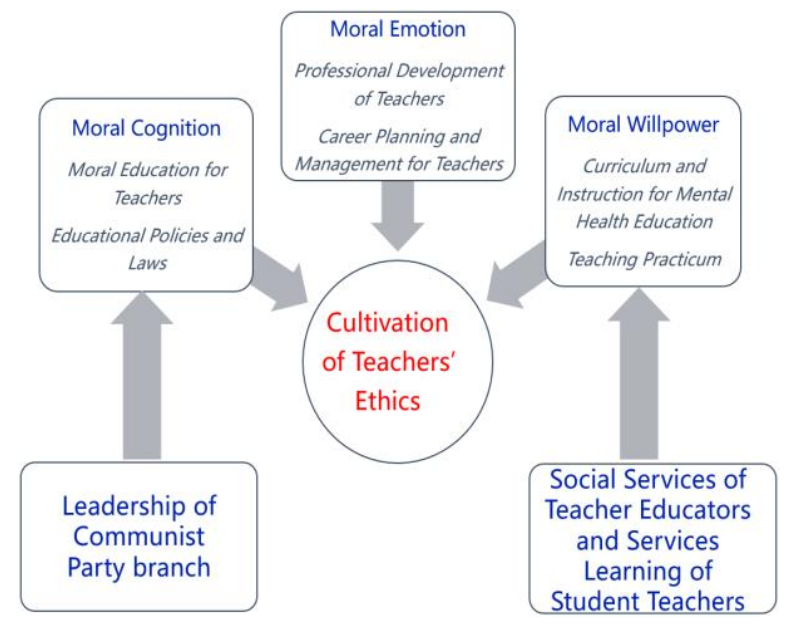

Figure 1 A new model consisting of "one core, three dimensions" in preparing "Four Haves" good teachers in mental health education

Three dimensions are interrelated each other [4]. Correct moral cognition is the basis and moral emotion is the motive of the formation of teachers' ethics. Moral willpower is the production of the interaction between of moral cognition and emotion. Only through three stages, we can achieve the goal of harmonious development of student teachers' ethics in cognition, emotion, and willpower.

Moreover, we found three main strategies of mental health education teacher preparation from perspective of ideological and political theory education in Linyi University, including (1) strengthening the leadership of Communist Party branch of Department of Psychology to provide a strong organizational guarantee for the ideological and political theory education, (2) returning to the original aspiration of teacher education, and innovating teaching practicum and curriculum system design in order to vigorously cultivate mental health education teachers who meet the "Four Haves" standard, (3) encouraging service learning and advocating voluntary public service for teacher educators and student teachers in order to cultivate teachers' ethics in the process of serving the society and Yimeng Area in Shandong Province. In the following section, we will discuss these strategies specifically.

\subsection{Communist Party Branch as a Strong Organization Guarantee}

Communist Party is the leader of the Party, the government, the army, and the people in China. The key to the Party's leadership over our department is to implement the Party's educational policy. It is a great responsibility for Communist Party to foster student teachers' character and civic virtue from perspective of ideological and political theory education in China.

\subsubsection{Regular Classes and Meetings of Communist Party Branch of Department of Psychology}

Regular classes and meetings of Communist Party branch of Department of Psychology are helpful to effectively improve the leadership in the ideological and political values education, and strengthen the sense of responsibility to make some effort in the ideological and political values education. We tried our best to integrate the tasks of professional teaching and the Party building. In October, 2016, Communist Party branch of the Department of Psychology was selected as an excellent case by Ministry of Education in exhibition of "two learnings and one doing". In 2018, our branch was appraised as the "Selected Model of Communist Party branch" in Linyi University. In April, 2020, it was approved as a unit that is being cultivated into the studio of Party branch secretary.

\subsubsection{Organizing Research Group to Study the principles of students' ideological and political theory education}

Adhering to the problem-orientated principle, in order to solve this important problem, that is, how to effectively 
carry out the pre-service teachers' ethics training, we organized a research group to discuss and revise the training plan collectively, and studied some systematic strategies to improve the effectiveness of professional ideological and political theory education. Communist Party branch of Department of Psychology makes use of the professional advantages of teaching and scientific research on such topics as mental health education, psychological counselling and psychological diagnosis etc. to deeply study the principles of students' ideological and political theory education and mental development and growth. Contemporary student teachers' values are becoming more and more diversified and individualized. In view of this trend, we should adjust the teaching methods of professional courses in time, and flexibly integrate ideological and political theory education into the content of professional courses according to different conditions, time and materials so as to better adapt to this trend.

\subsection{Innovative Teaching Practicum as a Solid Base of Curriculum System}

Linyi University has a tradition of teacher education for more than 70 years. However, with Linyi University becoming a comprehensive university, teacher education began to be marginalized, including our major, Applied Psychology. Applied Psychology Major was founded in 2005, whose orientation is general education. In 2016, Applied Psychology Major's orientation returned from general education back to teacher education. As gradual return to the original aspiration of teacher education, our major's orientation is getting clearer and clearer as follows.

(1) Taking pre-service teachers' ethics education as our own responsibility.

(2) Taking basic education and social needs in the Yimeng Area, Shandong Province as the guidance.

(3) Adapting to the requirements of mental health education in middle school.

(4) Training mental health education teachers with correct political values, noble morality, deep passion for education, innovative spirit and entrepreneurial ability, Yimeng Spirit and international vision, and humanistic and scientific literacy.

\subsubsection{Focusing on the Cultivation of Student Teachers' Ethics and Their Moral Education Ability}

Along the direction of teacher education, we focused on the cultivation of student teachers' ethics and their moral education ability according to the accreditation standards of related disciplines of teacher education.
Moreover, experts (leaders of Education Bureau, and mental health education teachers in middle school, etc.) are invited to optimize the training plan through several iterations, so as to integrate the cultivation of teachers' ethics into compulsory courses in a comprehensive, allround and three-dimensional manner. More specifically, courses such as "Entrance Education", "Teacher's Ethics Education" and "Education Policies and Laws" are aimed at cultivating student teacher's moral cognition, and courses such as "Teacher's Professional Development" and "Teacher's Career Planning and Management" are helpful to nurture student teacher's moral emotion, meanwhile courses such as "Teaching Practicum" and "Curriculum and Instruction of Mental Health Education" focus on the cultivation of teacher's moral willpower.

In 2017, the teaching team of Applied Psychology was awarded as the teaching team of "Huang Danian style" in Linyi University. In 2018, Department of Psychology was approved as the Social Science Popularization Education Base of Shandong Province (Research Center of Mental Health Education and Home Education). In 2019, a course of "Developmental Psychology" was approved as the first-class course in Shandong Province. In 2020, Applied Psychology Major was approved by Linyi University as the first-class major and is recommended as a Master's Degree Program of Applied Psychology in Shandong Province. On the basis of many years of practice and exploration in curriculum design and major building, our team had great achievements. For example, we won three provincial teaching achievement awards, and published two textbooks about "Educational Psychology", one textbook about "Psychology" and one textbook about "Mental Health Education and Mental Adjustment for University Students". The course of "Educational Psychology" has been successfully approved as a province-level excellent course.

\subsubsection{Redesigning the Teaching Practicum System according to the Partnership among the Government, University and Schools}

In the process of teaching practicum, we did our best to redesign the teaching practicum system according to the partnership among the government, university and schools. For many years, we have cooperated with the education administration departments and schools to implement reform actions through collaboration. For example, the mentorship model aimed at improving partnership between university mentors and school supervisors has been implemented for all student teachers during the whole process of teaching practicum. Every student teacher has two teacher educators to provide help and guidance, one university mentor and one school supervisor. According to the student teacher's learning style, ability and personality, the teacher educators guided the student teachers to carry out a series of training 
activities, including observation study, teaching practicum, survey study, dissertation thesis, innovation and entrepreneurship training, etc. In sum up, the mentorship model of university mentor/school supervisor can help student teachers consolidate their professional knowledge, improve their abilities of moral education and mental health education, broaden their moral cognition, and sublimate their moral emotion. In recent years, based on this mentorship model, we achieved one teaching research project of industry-university cooperation.

\subsubsection{Adjusting Teaching Methods of Theoretical Courses and Improving Teaching Quality}

In the teaching of theoretical courses, we should adhere to the teaching idea of "cultivating students with our heart", that is, be responsible for students with heart, and use psychological principles to stimulate students' intrinsic motivation of learning. In other words, we always take a students-center perspective, so we can constantly adjust teaching methods and improve teaching quality according to students' learning situations.

Associate professor Qing Hu was awarded as the most beautiful teacher of Linyi University in 2020. Most teachers in the department actively undertook one or two research projects about teaching reform, such as classroom model reform, student evaluation model reform, MOOC online course reform and so on. During the outbreak of COVID-19, all teachers responded positively to online teaching and established online education platforms (e.g. Dingtalk group, Wechat group etc.), which narrowed the distance between students, and greatly enhanced the teaching effect, and was deeply loved by students. Finally, our graduates are highly satisfied with our training. We used the 5-point Likert scale to investigate the satisfaction. Through paper and online surveys, the graduates report their satisfaction with teaching quality. The survey results suggested that in 2019 the percent of graduates' satisfaction with the overall quality of education and teaching was $98.3 \%$.

\subsection{Service Learning as an Important Strategy of Cultivating Teachers' Ethics}

Service learning can improve student teachers' sense of social responsibility and sublimate their moral emotion. Our major paid more attention on the implementation of social service work for teacher educators and student teachers, and we have made great achievements in social service work.

\subsubsection{Voluntary Public Service Provided by Student Teachers and Their Associations}

A number of outstanding student teachers and their associations have emerged who love voluntary public service. For example, Ziqi Huang, an undergraduate from grade 2014 majoring in Applied Psychology, volunteered to donate bone marrow to others. Because of this touching volunteer behaviour, she was awarded as the "National Star of University Students' Self-improvement". Department of Psychology named "Ziqi Volunteer Service Team" after her, and advocated student teachers to actively provide voluntary service for society. From January 13 to January 19, 2020, Ziqi Volunteer Service Team assisted Linyi Youth Volunteers Association to participate in the Spring Festival volunteer service activity. Volunteers guided passengers to move forward at the service desk in the hall, and quickly helped passengers to solve the problems of buying, collecting and changing tickets in front of the ticket vending machine. These volunteer behaviours created a safe and warm atmosphere for travel. On June 19, Ziqi Volunteer Service Team participated in the activity of "Lighting up Hope and Caring for Slow Angels" in the Central District of Zaozhuang City, helping to distribute materials for families of children with cerebral palsy [5].

Moreover, in the past four years, junior students majoring in applied psychology have been using the skills of peer counselling to help many peers to solve their mental problems. Through this volunteer activity, student teachers' skills of peer counselling have been improved and they have won two first-class prizes and one secondclass prize in Peer Counselling Competition in Shandong Province, and one second prize in National Student Teachers' Skills Competition. Benefit from these training, our graduates' mental health education skills are affirmed by employers, and employers are highly satisfied. We conducted a survey on the satisfaction of employer. More than 30 employers are selected every year through questionnaires or interviews. The survey results showed that over $90 \%$ of employers are very satisfied with the academic accomplishment of our graduates. Interviews results indicated that graduates had higher qualities in political values, moral values and professional performance. Our graduates are good at innovation, willing to contribute and dare to undertake hard work, which fully reflects the educational effect of our department.

\subsubsection{Social Services of Mental Health Counselling and Home Education Consultation Provided by Teacher Educators}

Teacher educators actively provide social services, such as mental health counselling and Home education consultation. With the goal of serving schools, Applied Psychology Major has developed the Research Center of Mental Health Education and Home Education of Linyi University, which contains two service teams: EAP (Employee Assistance Program) team and Home Education team. The EAP team cooperated with the Federation of Labor Unions in Linyi city to set up a 
psychological counselling service station. Both sides signed a regular service agreement aiming at providing long-term and free mental health services for employees in Linyi city. Meanwhile, Home Education team focused on serving adolescents and their families, which effectively popularized the scientific concepts and methods of Home education, finally formed a wellknown brand. By subdividing the service clients, the social service function of two teams are further strengthened. For example, in 2018, the Research Center of Mental Health Education and Home Education of Linyi University was approved as "Social Science Popularized Education Base in Shandong Province". Prof. Shujun Li and Prof. Yun Dong positively carried out the activities of "three walks into" (i.e. into the society, into the enterprise and into the community), "three sunshines" (i.e., teacher educators' teaching with sunshine, student teachers' mental health with sunshine and social psychology with sunshine). Three well-known brands of social service work were formed gradually, which are "Mental Health Service Station of Employees in Linyi City", "EAP Service Center in Linyi City" and "Parents' Reading Club decoding adolescence".

It should be noted that during a fight against COVID19 , a psychological assistance volunteer service team of more than 50 people was quickly established on the basis of our major. The hotline support, online psychological counselling, expert supervision, and so on were used to help the local administrative department responsible for epidemic prevention and control.

Teacher educators from Department of Psychology are also often invited to give lectures in enterprises, institutions and schools. Professor Jilin Zou once went to primary and secondary schools to give lectures about mental health of in-service teachers, which was warmly welcomed by the school. His lectures not only popularized the knowledge of psychology, but also helped teachers in primary and secondary schools establish a health ideal of mental growth.

\section{CONCLUSION}

In this case study, we proposed a new model and three strategies of mental health education teacher preparation from the perspective of ideological and political theory education in China. It is proved through practice that the model works well and these strategies are effective. But there are still some shortages, such as lack of relevant evidences about the development and growth of every student teachers' ethics as individual person. In the future, we should introduce new technologies such as big data to improve the effect of data tracking, improve the technology-driven ideological and political curriculum reform and strengthen the integration of ideological and political theory education into major curriculum and professional courses.

\section{AUTHORS' CONTRIBUTIONS}

Jilin Zou contributed to the design and implementation of the research and the analysis of the findings. Chengyan Yang contributed to the writing of the manuscript.

\section{ACKNOWLEDGMENTS}

This article is the part of Teaching Research Project in Linyi University "Experimental Psychology course development from ideological and political theory education", No. K2020SZ051 and 2020 Research Project of Teaching Change in Linyi University "Effect evaluation of mentorship model in online practicum of teacher education in the post-epidemic era", No. JG2020M13. Special thanks also are given to Prof. Qing $\mathrm{Hu}$ and Prof. Jinxia Zhao, who were concerned enough to take part in the management of our department.

\section{REFERENCES}

[1] Ministry of Education China. (2019) Notice on Strengthening and Improving the Construction of Teachers' Ethics and Virtue in the New Era. http://www.moe.gov.cn/srcsite/A10/s7002/201912/t 20191213_411946.html

[2] Department of teacher work of the Ministry of Education, Training good teachers in a great country, Education Science Press, 2018.

[3] E. Smith, Pitfalls and promises: The use of secondary data analysis in educational research, British Journal of Educational Studies 56(3) (2008) 323-339. DOI: https://doi.org/10.1111/j.14678527.2008.00405.x

[4] Jr. Murrell, M. E. Diez, S. Feiman-Nemser, \& D. L. Schussler. Teaching as a Moral Practice: Defining, Developing, and Assessing Professional Dispositions in Teacher Education, Harvard Education Press, 2010.

[5] Department of education Linyi University. Ziqi Volunteer Service Team participated in the "Light up Hope, Caring for Slow Angels" activity, https://jyxy.lyu.edu.cn/2020/0123/c7204a155275/p age.htm 